\title{
Produtividade e características tecnológicas de cultivares de feijão em resposta à calagem superficial em plantio direto
}

\author{
Tiago Roque Benetoli da Silva ('); Leandro Borges Lemos (2*); Carlos Alexandre Costa Crusciol (3) \\ (') Universidade Estadual de Maringá, Campus Regional de Umuarama, Estrada da Paca s/n (UEM - Fazenda), São Cristóvão, \\ Caixa Postal 65, 87501-970 Umuarama (PR),Brasil. E-mail: trbsilva@uem.br \\ (2) Universidade Estadual Paulista, Faculdade de Ciências Agrárias e Veterinárias, Departamento de Produção Vegetal, 14884-900 \\ Jaboticabal (SP). Bolsista do CNPq. E-mail: leandrobl@fcav.unesp.br $\left(^{*}\right)$ Autor correspondente. \\ (3) Universidade Estadual Paulista, Faculdade de Ciências Agronômicas, Departamento de Produção Vegetal, Caixa Postal 237, \\ 18603-970 Botucatu (SP). Bolsista do CNPq. E-mail: crusciol@fca.unesp.br
}

Recebido: 16/mar./2009; Aceito: 17/jul./2010

\section{Resumo}

O objetivo deste trabalho foi avaliar o efeito da aplicação superficial de calcário em plantio direto, na produtividade e nas características tecnológicas dos grãos de cultivares de feijão. O trabalho foi desenvolvido durante dois anos agrícolas, em Latossolo Vermelho distrófico, em condições de sequeiro. O delineamento experimental utilizado foi o de blocos casualizados em esquema de parcelas subdivididas, com quatro repetições. As parcelas foram representadas por cultivares de feijão (Carioca, IAC Carioca Eté, Pérola, IAPAR 81 e Campeão 2) e as subparcelas formadas pelas doses de calcário dolomítico (sem aplicação de calcário; 1,8; 3,6 e 5,4 t ha-1). As cultivares de feijão tiveram desenvolvimento produtivo distinto em função das doses de calcário aplicadas superficialmente no sistema plantio direto. A cultivar Campeão 2 foi mais produtiva nos dois anos de experimentação e a cultivar IAPAR 81 respondeu linearmente ao aumento das doses de calcário no segundo ano agrícola. Houve efeito da interação dos fatores cultivares $x$ doses de calcário para o tempo de cozimento, nos dois anos de experimentação, com aumento dessa característica na cultivar IAPAR 81, em função do incremento das doses de calcário. Comportamento semelhante foi obtido pela cultivar Pérola, porém apenas no segundo ano agrícola. O teor de proteína bruta variou de 210 a $230 \mathrm{~g} \mathrm{~kg}^{-1}$ e a relação de hidratação ficou próxima de 2,0 não sendo influenciados pelas doses de calcário e pelas cultivares de feijão.

Palavras-chave: Phaseolus vulgaris, acidez do solo, produtividade, proteína bruta, tempo de cozimento, hidratação dos grãos.

\section{Effects of liming on common bean yield and technological characteristics under no- tillage system}

\begin{abstract}
The objective of this study was to evaluate the effect of liming on yield and technological characteristics common bean cultivars under no-tillage system. The study was carried out during two crop seasons, on a dystrophic Red Latosol, under rainfed conditions. Responses were assessed using a split-plot design with four replications. The main plots were represented by the common bean cultivars (Carioca, IAC Carioca Eté, Pérola, IAPAR 81 and Campeão 2) and the split plots were represented by the rates of dolomitic limestone $\left(0 ; 1.8 ; 3.6\right.$ and $\left.5.4 \mathrm{t} \mathrm{ha}^{-1}\right)$. The cultivars differed in yield performance according to lime rates under no-tillage system. Campeão 2 had the best performance over the two years and IAPAR 81 responded linearly to the increasing lime rate on the second crop season. The interaction common bean cultivar $x$ lime rates had an effect on the cooking time of the beans. IAPAR 81 presented an increase in cooking time as the rate of lime was increased along the two crop seasons. Pérola had the same effect, but only on the second crop season. Crude protein ranged between $210 \mathrm{and} 230 \mathrm{~g} \mathrm{~kg}{ }^{-1}$ and hydration ratio was close to 2. Neither protein nor hydration ratio were influenced by lime rates or cultivars.
\end{abstract}

Key words: Phaseolus vulgaris, soil acidity, yield, crude protein, cooking time, grain hydration. 


\section{INTRODUÇÃO}

No Brasil, o feijoeiro comum (Phaseolus vulgaris L.) possui baixa produtividade média de gráos, em torno de $850 \mathrm{~kg} \mathrm{ha}^{-1}$, porém, em lavouras sob alta tecnologia e irrigadas, pode-se alcançar rendimentos superiores a 3.000 $\mathrm{kg} \mathrm{ha}^{-1}$, principalmente em sistemas de produção conservacionistas e sustentável como o plantio direto (SPD) e com cultivares adaptadas aos diversos agroecossistemas.

Dentre as causas para a baixa produtividade destacase a exploraçáo da cultura em áreas de sequeiro e marginal em termos de fertilidade natural do solo, associada ao pouco investimento em insumos agrícolas, como o uso de corretivos e fertilizantes (Barbosa Filho et al., 2005).

Devido à grande sensibilidade do feijoeiro à toxidez por alumínio e manganês, o uso de calcário está entre as práticas mais econômicas e fundamentais para a obtençáo de altas produtividades, fornecendo $\mathrm{Ca}$ e $\mathrm{Mg}$ como nutrientes, aumentando o $\mathrm{pH}$ do solo, bem como a disponibilidade de macronutrientes em função da neutralização da acidez, além de promover maior crescimento no sistema radicular pela melhoria das condições químicas do solo (Rosolem, 1996; Barbosa Filho et al., 2005).

Silva et al. (2004) avaliaram o sistema radicular de cultivares de feijão em resposta à calagem e verificaram que a cultivar Pérola foi mais tolerante à baixa saturaçáo por bases do que as cultivares Campeáo 1, Carioca e FT-Bonito; o máximo crescimento radicular das cultivares Campeão 1, Carioca e Pérola ocorreu com saturação por bases ao redor de $43 \%$. Observaram também que, em condiçóes de elevada acidez, o diâmetro radicular das cultivares foi reduzido e houve incremento em comprimento, além de a calagem ter promovido aumento do sistema radicular e da parte aérea das cultivares.

Segundo Thung e Oliveira (1998), na cultura do feijoeiro, o conceito de utilização de plantas mais tolerantes à toxicidade de alumínio ou responsivos a melhoria do ambiente solo em termos de seus atributos químicos, bem como os mecanismos que conferem essa característica à cultivar não está bem caracterizado ou elucidado.

Trabalho desenvolvido por SiLva et al. (2007), objetivando avaliar a eficiência de utilização de nutrientes em cultivares de feijāo (Campeão 1, Carioca, FT-Bonito e Pérola,) em razão da calagem, verificaram que em solo ácido e na ausência de calcário, a cultivar Carioca destacouse na eficiência de utilização de $\mathrm{P}$ e Ca, sendo a Campeão 1 mais eficiente na utilização de $\mathrm{N}$ e $\mathrm{K}$. Também verificaram que com o aumento dos níveis de calcário, a cultivar Pérola foi mais eficiente na utilizaçáo de $\mathrm{N}$, seguido por FT-Bonito e Carioca. A cultivar FT-Bonito destacou-se quanto à utilizaçấo eficiente de $\mathrm{P}$ e todas as cultivares de feijão foram eficientes na utilização de $\mathrm{Zn}$, com o aumento dos níveis de calcário.

A crescente adoção do SPD vem promovendo a elevação da produtividade de grãos de feijão, pois ao longo dos anos, o feijoeiro tornou-se uma das principais culturas de entressafra principalmente na Região Central e Sudeste do Brasil (Fageria e Stone, 2004).

No SPD existe grande interesse na busca de formas alternativas para o estabelecimento do sistema sem incorporação prévia do calcário, realizando-se a calagem superficial desde o início de sua implantação, tendo como vantagens a manutençấo dos atributos químicos e da estrutura do solo, maior controle da erosão e economia de energia com a eliminação das operações de incorporaçáo de calcário e preparo do solo, bem como o aumento da capacidade de exploração de água e de nutrientes do subsolo pelo sistema radicular das plantas (Mello et al., 2003; Barbosa Filho et al., 2005).

A aplicação de corretivos de acidez de solo tem apresentado resultados positivos ao longo dos anos nos atributos químicos do solo, desenvolvimento do sistema radicular, da parte aérea, bem como na produtividade do feijoeiro (Barbosa Filho et al., 2005; Silva et al., 2007).

No Brasil e na cultura do feijoeiro, pouco se sabe sobre a influência da calagem no comportamento das cultivares e de possíveis modificações nas características nutricionais e tecnológicas, como o teor de proteína bruta, tempo de cocção e capacidade de hidratação dos grãos. $\mathrm{O}$ único trabalho que trata o assunto foi desenvolvido por MoraEs et al. (1998) no qual avaliaram o efeito de doses de calcário $\left(0 ; 1,4\right.$ e $\left.2,8 \mathrm{t} \mathrm{ha}^{-1}\right)$ e gesso $(0 ; 130 ; 260$ e $390 \mathrm{~kg}$ ha $\left.^{-1}\right)$ na produtividade de grãos, no tempo de cozimento e na relação de hidratação do feijão, cultivar Carioca 80. Esses autores verificaram que as doses de calcário e gesso não afetaram a produtividade e a relação de hidrataçáo dos grãos. No entanto, o tempo de cozimento aumentou com o acréscimo das doses de calcário e gesso.

O objetivo deste trabalho foi avaliar a influência da aplicação superficial de calcário no sistema plantio direto e o comportamento de cultivares de feijão quanto à produtividade e características tecnológicas dos grãos.

\section{MATERIAL E MÉTODOS}

Foi desenvolvido um experimento no município de Botucatu (SP), a $22^{\circ} 51^{\prime}$ Sul, $48^{\circ} 26^{\prime}$ Oeste, com altitude de $740 \mathrm{~m}$. De acordo com os critérios da classificação de Köppen, o clima da região é Cfa, temperado (mesotérmico), constantemente úmido, tendo quatro ou mais meses com temperaturas médias superiores a $10{ }^{\circ} \mathrm{C}$, sendo a temperatura do mês mais quente igual ou superior a $22^{\circ} \mathrm{C}$.

O solo do local foi classificado de acordo com Embrapa (2006), como Latossolo Vermelho Distrófico, textura franco-argilosa, com saturaçáo por bases de $41 \%$ e capacidade de troca catiônica (CTC) de $98 \mathrm{mmol}_{c}$ $\mathrm{dm}^{-3}$. O solo ficou dois anos em pousio e, em fevereiro de 2001 foi preparado com uma aração e duas gradagens. 
Posteriormente, realizou-se a semeadura de soja (safrinha). Em agosto de 2001, a área experimental foi subsolada, e em 3 de novembro de 2001, semeou-se guandu, manejado com triton e herbicida, permanecendo em pousio até setembro de 2002, quando se realizou o controle químico de plantas daninhas. Em outubro de 2002, realizou-se aplicação de calcário superficialmente e em novembro, a semeadura de milheto, iniciando-se o experimento.

Ao longo de 2003 e 2004, utilizou-se a seguinte sucessão de culturas: milheto (primavera) - feijão (verão) - aveia preta (outono-inverno), em condiçóes de sequeiro, e no SPD.

O delineamento experimental utilizado foi o de blocos casualizados disposto em um esquema de parcelas subdivididas. As parcelas foram constituídas por cinco cultivares de feijão (Carioca, IAC Carioca Eté, Pérola, IAPAR 81 e Campeão 2) e as subparcelas formadas por quatro doses de calcário dolomítico $\left(0 ; 1,8 ; 3,6\right.$ e 5,4 t ha- ${ }^{-1}$, ou seja, sem aplicaçáo de calcário, quantidade de calcário para elevar a saturação por bases a 54\%, 68\% e $80 \%$ respectivamente), totalizando 20 tratamentos, com quatro repetições. As subparcelas foram constituídas por 10 linhas de seis metros de comprimento, considerando como área útil as oito linhas centrais, desprezando-se $0,5 \mathrm{~m}$ em cada extremidade, nos dois anos de experimentação.

O calcário, aplicado manualmente em 15/10/2002, tinha $72 \%$ de poder relativo de neutralização total (PRNT), 84,3\% de poder de neutralização (PN), 84,5\% de reatividade (RE), 23,3\% de $\mathrm{CaO}$ e $17,5 \%$ de $\mathrm{MgO}$. Em seguida, realizou-se a semeadura do milheto (cv. $\mathrm{BN}-2$ ), no espaçamento de 0,22 metros, com $35 \mathrm{~kg}$ de sementes ha $\mathrm{ha}^{-1}$, utilizando-se $100 \mathrm{~kg} \mathrm{ha}^{-1}$ do fertilizante formulado 4-20-10.

A semeadura das cultivares de feijáo foi realizada em 19/12/2002 e 17/12/2003, e seu desenvolvimento ocorrido durante o período de verão, em condiçôes de sequeiro. As sementes foram tratadas com thiamethoxam $(140 \mathrm{~g}$ de i.a. $/ 100 \mathrm{~kg}$ de sementes) e com anilida+ditiocarbamato $(40+40 \mathrm{~g}$ do i.a. $/ 100 \mathrm{~kg}$ de sementes). A semeadura foi realizada com auxílio de semeadora, regulada para 15 sementes por metro de sulco, em espaçamento entrelinhas de $0,45 \mathrm{~m}$, obtendo-se uma densidade de 240.000 plantas $\mathrm{ha}^{-1}$. A emergência das plântulas ocorreu em 25/12/2002 e 23/12/2003 respectivamente.

A adubação mineral de base utilizada foi $300 \mathrm{~kg} \mathrm{ha}^{-1}$ da fórmula 4-20-10 no primeiro ano e $280 \mathrm{~kg} \mathrm{ha}^{-1} \mathrm{da}$ fórmula 4-14-8 no segundo ano agrícola. A adubação de cobertura, nos dois anos agrícolas, foi realizada no início do estádio fenológico $V_{4}$, caracterizado pela presença da terceira folha trifoliolada, completamente aberta em 50\% das plantas, na dose de $70 \mathrm{~kg} \mathrm{ha}^{-1}$ de N, utilizando como fonte a uréia (Ambrosano et al., 1997).

Com relação aos tratos fitossanitários, aplicaram-se inseticida (deltramethrina) e fungicidas (azoxystrobin e tebuconazole), nas doses de $0,15 \mathrm{~L} \mathrm{ha}^{-1}, 25 \mathrm{~g} \mathrm{ha}^{-1}$ e 0,1
$\mathrm{L} \mathrm{ha}^{-1}$ de i.a. respectivamente. Para o controle de plantas daninhas, utilizou-se herbicida em pós-emergência (bentazon e fenoxaprop-p-ethyl) nas doses de 200 e $250 \mathrm{~mL}$ de i.a. ha ${ }^{-1}$ respectivamente. O florescimento pleno $\left(\mathrm{R}_{6}\right)$ e a colheita ocorreram, nos dois anos agrícolas, aos 36 e 83 dias após a emergência das plântulas respectivamente.

A produtividade de grãos foi estimada em $\mathrm{kg} \mathrm{ha}^{-1}$, após a colheita de todas as plantas contidas na área útil de cada subparcela, padronizando o teor de água nos grãos para $13 \%$.

O teor de proteína bruta ( $\mathrm{PB} \%)$ foi determinado pela fórmula: $\mathrm{PB}=\mathrm{N}_{\text {total }} 6,25$, em que $\mathrm{N}_{\text {total }}$ é o teor de $\mathrm{N}$ nos gráos, obtido pelo método de Kjedahl, seguindo a metodologia de Sarruge e HaAg (1974).

O tempo de cozimento (minutos) dos grãos foi determinado com o auxílio do cozedor de Mattson, com água mantida em nível constante e temperatura de $96^{\circ} \mathrm{C}$ (Lemos et al., 2004 e Silva et al., 2006). De posse dos dados, adotou-se a escala de Proctor e Watts (1987) para verificar o nível de resistência ao cozimento.

A capacidade de hidratação foi determinada em amostras de 50 gramas colocadas em água destilada durante 12 horas, segundo metodologia descrita por Lemos et al. (2004) e Silva et al. (2006). Nas primeiras 4 horas, o volume de água absorvida foi determinado a cada 30 minutos e nas 8 horas restantes, a cada hora. No fim do tempo para a hidratação, a água foi totalmente drenada e os grãos pesados. Os grãos não hidratados, denominados de "casca dura" (hardshell) foram separados e pesados, com o valor expresso em porcentagem. A relação de hidratação foi determinada como a razão entre a massa após o término da avaliaçáo e a massa inicial dos grâos. Realizou-se a análise de regressão polinomial entre o tempo (horas) e a capacidade de hidratação pelo volume de água absorvido $(\mathrm{mL})$ para se determinar o tempo necessário para a máxima hidratação dos grãos, segundo metodologia de Lemos et al. (2004) e SiLva et al. (2006). Durante a condução do teste, a temperatura média da água foi de $24^{\circ} \mathrm{C}$.

Os atributos químicos do solo como acidez ativa $(\mathrm{pH})$, teor de cálcio $(\mathrm{Ca})$, magnésio $(\mathrm{Mg})$, saturação por bases $(\mathrm{V})$, acidez potencial $(\mathrm{H}+\mathrm{Al})$ e teor de alumínio (Al), foram determinados seguindo a metodologia de Raij e Quaggio (1983), nas profundidades de 0-5, 5-10, 10-20 e 20-40 cm, sendo as amostras de solo retiradas com o auxílio de trado, em seis pontos por parcela, antes e após seis e 18 meses da aplicação de calcário superficialmente.

Os dados foram submetidos à análise de variância, utilizando-se o teste $\mathrm{F}$ e a análise de regressão para avaliar as doses de calcário. Os dados provenientes das cultivares foram comparados pelo teste de Tukey. Realizou-se também, o estudo de regressão polinomial para os atributos químicos do solo, após seis e 18 meses da aplicação de calcário superficialmente. 


\section{RESULTADOS E DISCUSSÃO}

Com relação à produtividade de grãos, verificou-se que, no primeiro ano agrícola, somente houve diferença significativa entre cultivares, destacando-se a cultivar Campeão $2 \mathrm{com} 1.630 \mathrm{~kg} \mathrm{ha}^{-1}$ (Tabela 1). A cultivar IAC Carioca Eté proporcionou menor produtividade de grãos $\left(960 \mathrm{~kg} \mathrm{ha}^{-1}\right)$, ou seja, com apenas $59 \%$ do que produziu a cultivar Campeão 2.

De forma geral, após seis meses da aplicação de calcário, houve melhoria nos atributos químicos do solo com o aumento do $\mathrm{pH}$, teores de cálcio e magnésio e saturação por bases, bem como a redução da acidez potencial e do teor de alumínio, porém apenas em valores médios, o que não foi constatado pelo estudo de regressão polinomial (Tabela 2). Essa situação não foi suficiente para ocasionar efeito positivo na produtividade das cultivares (Tabela 1). A capacidade produtiva das cultivares pode ter sido influenciada pelas condiçôes climáticas, pois de $1 .^{\circ}$ a 12/2/2003 não houve precipitação pluvial e as temperaturas ultrapassaram $32^{\circ} \mathrm{C}$, coincidindo com o período de florescimento pleno $\left(\mathrm{R}_{6}\right)$, como pode ser observado nas figuras 1 e 2. De acordo com Didonet (2002), existe variabilidade genotípica quanto ao efeito do estresse hídrico e altas temperaturas no florescimento e enchimento de vagens do feijoeiro, fazendo com que as cultivares se desenvolvam de maneira diferenciada. O estresse hídrico aliado à temperatura elevada nesse estádio fenológico da cultura pode proporcionar redução no número de vagens por planta, por causa do abortamento floral, acarretando diminuição na produtividade.

A produtividade de grãos no segundo ano foi maior que a do primeiro ano, para todos os tratamentos (Tabela 1). A cultivar Campeáo 2 destacou-se mais uma vez quanto à produtividade, obtendo-se $2.709 \mathrm{~kg} \mathrm{ha}^{-1}$. A cultivar IAC Carioca Eté, apesar da melhoria no desempenho produtivo, comparativamente ao primeiro ano, também obteve o menor rendimento, porém sem diferir estatisticamente da cultivar Carioca, Pérola e IAPAR 81. A melhoria na produtividade, no segundo ano agrícola deve-se as condiçôes climáticas, com temperatura e precipitação pluvial adequadas, tanto na fase vegetativa quanto na reprodutiva, principalmente nos estádios fenológicos de florescimento pleno $\left(R_{6}\right)$ até o enchimento das vagens $\left(\mathrm{R}_{8}\right)$ (Figuras 1 e 2). Além disso, a aplicação de doses crescentes de calcário resultou em aumento linear na produtividade da cultivar IAPAR 81 (Tabela 3), evidenciando os efeitos benéficos que a prática da calagem exerce no feijoeiro (Barbosa Filho et al., 2005; Silva et al., 2004). Esse fato pode ser comprovado em função da melhoria dos atributos químicos do solo, por meio da elevação nos teores de $\mathrm{pH}$, Ca e V na profundidade de 0-5 e $5-10 \mathrm{~cm}$, acréscimos nos teores de $\mathrm{Mg}$ na profundidade de 0-5, 5-10, 10-20 e 20-40 cm, além da redução nos teores de $\mathrm{H}+\mathrm{Al}$, na profundidade de $0-5 \mathrm{~cm}$, após 18 meses da aplicação superficial das doses de calcário (Tabela 2). Resultados semelhantes foram obtidos por Mello et al. (2003), em Latossolo Vermelho distrófico, onde a aplicação de

Tabela 1. Produtividade de grãos, tempo de cozimento (minutos) e teor de proteína bruta, em função de cultivares de feijão e doses de calcário $\left(\mathrm{t} \mathrm{ha}^{-1}\right)$ aplicado superficialmente em plantio direto

\begin{tabular}{|c|c|c|c|c|c|c|}
\hline \multirow{2}{*}{ Tratamento } & \multicolumn{2}{|c|}{ Produtividade de grãos } & \multicolumn{2}{|c|}{ Teor de proteína bruta } & \multicolumn{2}{|c|}{ Tempo de cozimento } \\
\hline & 2003 & 2004 & 2003 & 2004 & 2003 & 2004 \\
\hline Cultivares & \multicolumn{2}{|c|}{ kg ha $^{-1}$} & \multicolumn{2}{|c|}{$\mathbf{g ~ k g}^{-1}$} & \multicolumn{2}{|c|}{ mim } \\
\hline Carioca & $1.460 \mathrm{~b}$ & $2.333 b$ & $210 a$ & $220 \mathrm{a}$ & $28 c$ & $30 \mathrm{~b}$ \\
\hline IAC Carioca Eté & $960 \mathrm{~d}$ & $2.094 b$ & $230 \mathrm{a}$ & $230 \mathrm{a}$ & $27 c$ & $32 b$ \\
\hline Pérola & $1.250 \mathrm{c}$ & $2.367 \mathrm{~b}$ & $230 \mathrm{a}$ & $220 \mathrm{a}$ & 35 a & $40 \mathrm{a}$ \\
\hline IAPAR 81 & $1.340 \mathrm{bc}$ & $2.291 b$ & $220 \mathrm{a}$ & $220 \mathrm{a}$ & $32 \mathrm{~b}$ & $37 a$ \\
\hline Campeão 2 & $1.630 \mathrm{a}$ & $2.709 \mathrm{a}$ & $230 \mathrm{a}$ & $230 \mathrm{a}$ & 37 a & $30 \mathrm{~b}$ \\
\hline C.V. (\%) & 9,1 & 10,5 & 8,2 & 5,5 & 8,4 & 8,9 \\
\hline Doses de calcário & & $\left({ }^{1}\right)$ & & & & $\left({ }^{2}\right)$ \\
\hline 0 & 1.390 & 2.180 & 230 & 220 & 31 & 31 \\
\hline 1,8 & 1.280 & 2.390 & 220 & 220 & 32 & 33 \\
\hline 3,6 & 1.340 & 2.400 & 220 & 220 & 32 & 34 \\
\hline 5,4 & 1.250 & 2.460 & 230 & 220 & 32 & 38 \\
\hline C.V. (\%) & 11,8 & 10,9 & 6,8 & 5,7 & 6,4 & 6,3 \\
\hline F Cultivares (C) & $* *$ & $* *$ & n.s. & n.s. & $* *$ & $* *$ \\
\hline F Doses (D) & n.s. & $* *$ & n.s. & n.s. & n.s. & $* *$ \\
\hline F Interação C x D & n.s. & * & n.s. & n.s. & $* *$ & $* *$ \\
\hline R.L. & n.s. & * & n.s. & n.s. & n.s. & $* *$ \\
\hline R.Q. & n.s. & n.s. & n.s. & n.s. & n.s. & n.s. \\
\hline
\end{tabular}

(') $Y=45,33 x+2238,6 ; R^{2}=0,80 .\left(^{2}\right) Y=1,2222 x+30,7 ; R^{2}=0,93$.

Médias seguidas de mesma letra, na coluna, dentro do fator cultivares, năo diferem entre si a $5 \%$ pelo teste de Tukey. ${ }^{\text {n.s. }}$ : Não significativo. ${ }^{*}$ e ${ }^{* *}$ : Significativo a 5 e $1 \%$ de probabilidade pelo teste F respectivamente.

R.L. = Regressão linerar. R.Q. = Regressão quadrática. 
calcário superficial no SPD, alterou positivamente os atributos químicos do solo, na profundidade de $0-5$ e 5-10 $\mathrm{cm}, 12$ meses após a calagem.

Destaca-se também, o ganho em produtividade de um ano para o outro, quando náo foi utilizado calcário obtendo-se $1.390 \mathrm{~kg} \mathrm{ha}^{-1}$ em 2003 e, valores variando de 2.015 a $2.491 \mathrm{~kg} \mathrm{ha}^{-1}$ em 2004 (Tabelas 1 e 3 respectivamente). Esses valores podem estar relacionados ao fato de no segundo ano agrícola da sucessão de culturas (aveiapreta/milheto/feijāo) ter aumentado a disponibilidade de nutrientes, com melhoria nas condiçôes do solo, aliado ao clima favorável e às práticas culturais adequadas.

Ainda no segundo ano agrícola verificaram-se diferenças na interação cultivares x doses de calcário (Tabela 3), em que somente a produtividade da cultivar IAPAR 81 se ajustou em uma regressão linear, ou seja, não atingiu o máximo rendimento de grãos com a aplicação das doses de calcário. Assim, sugere-se que essa cultivar pode ser recomendada para cultivos em solos altamente corrigidos quanto à acidez, decorrente da responsividade do material, em relação às práticas culturais utilizadas.

Quanto ao teor de proteína bruta, verificou-se que não houve influência dos tratamentos, com variação de 210 a $230 \mathrm{~g} \mathrm{~kg}^{-1}$ (Tabela 1). No entanto, Vale e NakagaWA (1996) observaram que a aplicação de calcário quando incorporado ao solo, proporcionou aumento no teor de proteína bruta nas cultivares Carioca e Emgopa 201 Ouro. Deve-se destacar que não foram constatados outros

Tabela 2. Acidez ativa $\left(\mathrm{pH}\right.$ em $\left.\mathrm{CaCl}_{2}\right)$, teores de cálcio e magnésio ( $\mathrm{Ca}$ e $\left.\mathrm{Mg}, \mathrm{mmol}_{\mathrm{c}} \mathrm{dm}^{-3}\right)$, saturação por bases $(\mathrm{V}$ em $\%)$, acidez potencial $\left(\mathrm{H}+\mathrm{Al} \mathrm{em} \mathrm{mmol}_{\mathrm{c}} \mathrm{dm}^{-3}\right)$ e teor de alumínio $\left(\mathrm{Al} \mathrm{em} \mathrm{mmol}_{\mathrm{c}} \mathrm{dm}^{-3}\right)$ de um Latossolo Vermelho, antes e após seis e 18 meses da aplicação de calcário superficialmente em plantio direto

\begin{tabular}{|c|c|c|c|c|c|}
\hline \multirow{3}{*}{$\begin{array}{l}\text { Profundidade } \\
\mathrm{cm}\end{array}$} & \multicolumn{5}{|c|}{$\mathrm{pH}$} \\
\hline & Antes & \multicolumn{2}{|c|}{6 meses } & \multicolumn{2}{|c|}{18 meses } \\
\hline & & & - & & \\
\hline $0-5$ & 4,8 & $\hat{Y}=\bar{Y}=5,6\left({ }^{1}\right)$ & - & $\hat{Y}=0,41 x+4,4$ & $0,97^{* *}\left({ }^{2}\right)$ \\
\hline $5-10$ & 4,8 & $\hat{Y}=\bar{Y}=5,5$ & - & $\hat{Y}=0,2 x+4,9$ & $0,98^{* *}$ \\
\hline $10-20$ & 4,6 & $\hat{Y}=\bar{Y}=4,9$ & - & $\hat{Y}=\bar{Y}=5,4$ & - \\
\hline \multirow[t]{3}{*}{$20-40$} & 4,2 & $\hat{Y}=\bar{Y}=4,3$ & - & $\hat{Y}=\bar{Y}=4,5$ & - \\
\hline & \multicolumn{5}{|c|}{$\mathrm{Ca}$} \\
\hline & Antes & \multicolumn{2}{|c|}{6 meses } & \multicolumn{2}{|c|}{18 meses } \\
\hline $0-5$ & 27,0 & $\hat{Y}=2,49 x+27,6$ & $0,91^{*}$ & $\hat{Y}=4,2 x+23,1$ & $0,91^{* *}$ \\
\hline $5-10$ & 31,5 & $\hat{Y}=\bar{Y}=34,5$ & - & $\hat{Y}=6,1 X+16,6$ & $0,71^{*}$ \\
\hline $10-20$ & 24,5 & $\hat{Y}=\bar{Y}=18,1$ & - & $\hat{Y}=\bar{Y}=22,3$ & - \\
\hline \multirow[t]{3}{*}{$20-40$} & 18,7 & $\hat{Y}=\bar{Y}=11,4$ & - & $\hat{Y}=\bar{Y}=10,9$ & - \\
\hline & \multicolumn{5}{|c|}{ Mg } \\
\hline & Antes & \multicolumn{2}{|c|}{6 meses } & \multicolumn{2}{|c|}{18 meses } \\
\hline $0-5$ & 11,4 & $\hat{Y}=\bar{Y}=21,6$ & - & $\hat{Y}=2,96 x+9,3$ & $0,90^{* *}$ \\
\hline $5-10$ & 14,9 & $\hat{Y}=\bar{Y}=20,6$ & - & $\hat{Y}=2,51 x+8,5$ & $0,79^{* *}$ \\
\hline $10-20$ & 9,8 & $\hat{Y}=\bar{Y}=13,2$ & - & $\hat{Y}=0,75 x+10,0$ & $0,60^{*}$ \\
\hline \multirow[t]{3}{*}{$20-40$} & 5,6 & $\hat{Y}=\bar{Y}=5,9$ & - & $\hat{Y}=0,71 x+4,25$ & $0,89^{*}$ \\
\hline & \multicolumn{5}{|c|}{ v } \\
\hline & Antes & \multicolumn{2}{|c|}{6 meses } & \multicolumn{2}{|c|}{18 meses } \\
\hline $0-5$ & 41,3 & $\hat{Y}=\bar{Y}=64,4$ & - & $\hat{Y}=12,6 x+37,9$ & $0,98^{* *}$ \\
\hline $5-10$ & 45,6 & $\hat{\mathrm{Y}}=\overline{\mathrm{Y}}=64,3$ & - & $\hat{Y}=4,9 x+47,8$ & $0,74^{* *}$ \\
\hline $10-20$ & 35,5 & $\hat{Y}=\bar{Y}=42,4$ & - & $\hat{Y}=\bar{Y}=49,1$ & - \\
\hline \multirow[t]{3}{*}{$20-40$} & 23,2 & $\hat{Y}=\bar{Y}=19,9$ & - & $\hat{Y}=\bar{Y}=22,6$ & - \\
\hline & \multicolumn{5}{|c|}{$\mathrm{H}+\mathrm{Al}$} \\
\hline & Antes & \multicolumn{2}{|c|}{6 meses } & \multicolumn{2}{|c|}{18 meses } \\
\hline $0-5$ & 52,4 & $\hat{Y}=\bar{Y}=31,9$ & - & $\hat{Y}=-8 x+48,3$ & $0,81^{* *}$ \\
\hline $5-10$ & 56,4 & $\hat{Y}=\bar{Y}=31,2$ & - & $\hat{Y}=\bar{Y}=31,1$ & - \\
\hline $10-20$ & 65,1 & $\hat{Y}=\bar{Y}=52,0$ & - & $\hat{Y}=\bar{Y}=36,1$ & - \\
\hline \multirow[t]{3}{*}{$20-40$} & 84,5 & $\hat{Y}=\bar{Y}=80,2$ & - & $\hat{Y}=\bar{Y}=79,1$ & - \\
\hline & \multicolumn{5}{|c|}{ Al } \\
\hline & Antes & \multicolumn{2}{|c|}{6 meses } & \multicolumn{2}{|c|}{18 meses } \\
\hline $0-5$ & 3,6 & $\hat{Y}=\bar{Y}=1,9$ & - & $\hat{Y}=\bar{Y}=1,3$ & - \\
\hline $5-10$ & 4,2 & $\hat{Y}=\bar{Y}=2,1$ & - & $\hat{Y}=\bar{Y}=2,3$ & - \\
\hline $10-20$ & 7,4 & $\hat{Y}=\bar{Y}=3,2$ & - & $\hat{Y}=\bar{Y}=5,8$ & - \\
\hline $20-40$ & 14,6 & $\hat{Y}=\bar{Y}=8,5$ & - & $\hat{Y}=\bar{Y}=10,8$ & - \\
\hline
\end{tabular}


trabalhos que correlacionassem o teor de proteína bruta com a aplicação superficial de calcário, o que mostra a necessidade da realização de outras pesquisas, visto que essa característica é influenciada por outros fatores, como o local de cultivo, de condiçóes ambientais, da cultivar e do manejo da adubação nitrogenada (SiLva et al., 2006).

Quanto ao tempo de cozimento, observou-se efeito significativo de cultivares e da interação cultivares $\mathrm{x}$ doses de calcário, nos dois anos de experimentaçáo (Tabela 1). Esses resultados corroboram com os de Lemos et al. (2004), quando verificaram que o tempo de cozimento do feijão foi influenciado pela interação genótipos x ambiente.
Os dados do tempo de cozimento da cultivar IAPAR 81 no primeiro ano se ajustaram à regressão linear, o mesmo ocorrendo no segundo ano, juntamente com a cultivar Pérola (Tabela 4), ou seja, à medida que aumentou as doses de calcário aplicado superficialmente, maior foi o tempo de cocção. Resultados semelhantes foram obtidos por Moraes et al. (1998). Esses autores verificaram que com o aumento das doses de calcário e de gesso, o tempo de cozimento da cultivar Carioca 80 elevou-se de forma quadrática e linear respectivamente.

O tempo de cozimento da cultivar IAPAR 81variou de 28 a 35 minutos e de 32 a 43 minutos nos dois anos de

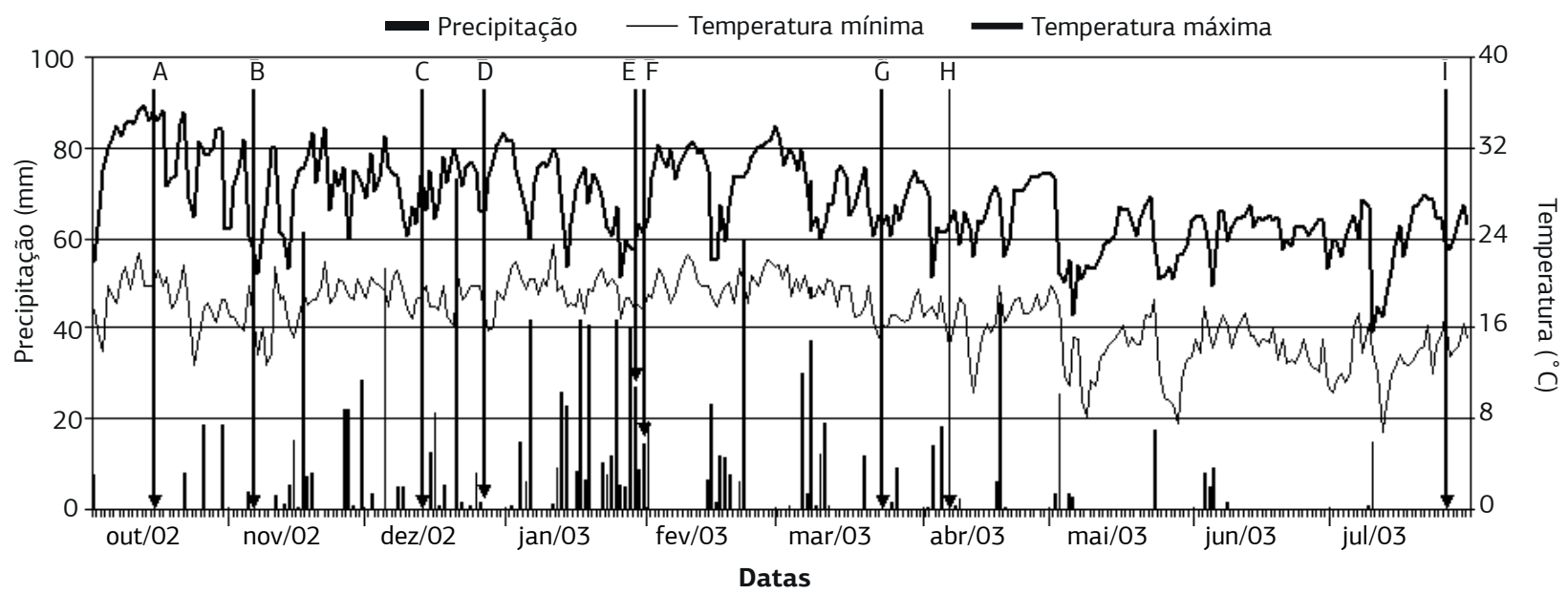

Figura 1. Precipitação pluvial e temperatura mínima e máxima registradas durante o manejo do experimento em Botucatu (SP), $2002 / 2003$. A - aplicação do calcário; B - semeadura do milheto; C - manejo do milheto; D - emergência do feijão; E - florescimento da cultivar IAC Carioca Eté; F - florescimento das outras cultivares; G - colheita do feijão; H - semeadura da aveia preta; I - florescimento da aveia preta.

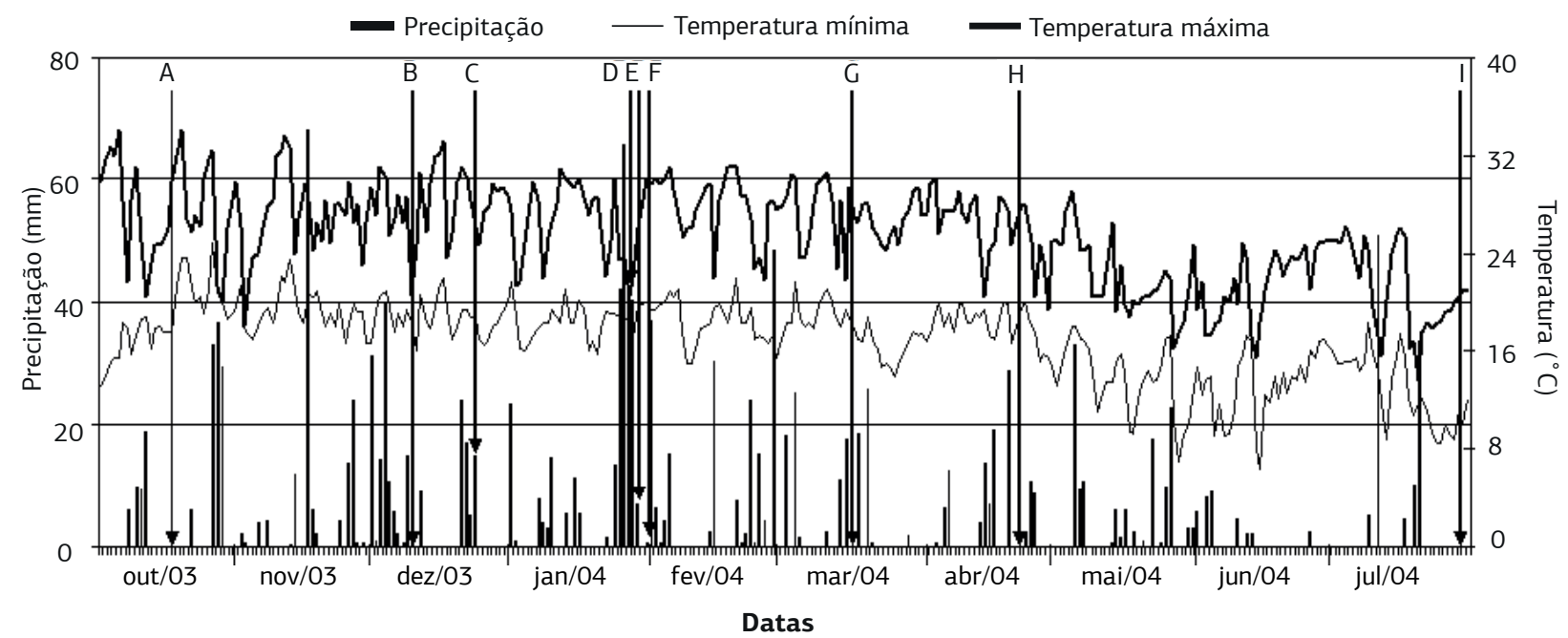

Figura 2. Precipitação pluvial e temperatura mínima e máxima registradas durante o manejo do experimento em Botucatu (SP), $2003 / 2004$. A - semeadura do milheto; B - manejo do milheto; C - emergência do feijão; D - florescimento da cultivar Carioca; $\mathrm{E}$ - florescimento das cultivares Pérola, IAPAR 81 e Campeão 2; F - florescimento da cultivar IAC Carioca Eté; G - colheita do feijão; H - semeadura da aveia preta; I - florescimento da aveia preta. 
experimentação (Tabela 4). Comparando-se os resultados do tempo para cozimento com os níveis de resistência à cocção sugeridos por Proctor e Watts (1987), esses valores enquadram-se como resistência normal e resistente a cocção no primeiro ano e resistência média a muito resistente à cocção no segundo ano. A cultivar Pérola obteve tempo de cozimento variando de 38 a 43 minutos no segundo ano (Tabela 4), e de acordo com Proctor e WatTs (1987), esses valores expressam muita resistência à cocção.

Segundo SARTORI (1996), o amolecimento das sementes de leguminosas durante o cozimento envolve a dissolução ou a desintegração da lamela média, com consequente separação das células e a reação dos fitatos, de sódio ou de potássio, do citoplasma intercelular com pectatos de cálcio ou de magnésio presentes nas paredes celulares e na lamela média. Esta reação resulta na conversão dos pectatos insolúveis de cálcio ou de magnésio em pectatos solúveis de sódio ou de potássio. Portanto, a aplicação das doses de calcário pode ter promovido aumento no teor de Ca nos grãos, interferindo na rigidez da membrana e nas paredes celulares.

De forma geral, no tegumento dos grãos são observadas as maiores quantidades de pectatos de cálcio, que intervém na divisão e alongamento celular, pois quanto mais espesso for o tegumento, maior a dificuldade na absorção de água (MArschner, 1995). Na cultura do feijoeiro não foram verificados trabalhos com esse nível de detalhamento, porém em razão dos resultados, verifica-se a necessidade de maior investigação científica, nessa linha de pesquisa, visto que períodos longos de cocção podem causar mudanças estruturais nas células, promovendo a perda de nutrientes e maior gasto no preparo de alimento e energia.

Com relação aos grãos de casca dura, houve diferença estatística entre as cultivares (Tabela 5). No primeiro ano, os valores variaram de $4,34 \%$ a $0,75 \%$, obtidas pelas cultivares Pérola e Carioca respectivamente. No segundo ano, os valores variaram de 1,85\% a $0,18 \%$, obtidas pelas cultivares IAC Carioca Eté e Campeão 2 respectivamente. $\mathrm{O}$ percentual de grãos de casca dura foi expresso com menor intensidade pela cultivar Carioca no primeiro ano e, pela cultivar Campeão 2 no segundo ano. No entanto, tais valores são considerados baixos ou de reduzida intensidade, revelando que esta característica é influenciada pela interação genótipos $\mathrm{x}$ ambiente (Lemos et al., 2004).

Tabela 3. Desdobramento da interação da produtividade de grãos (2004), em função de cultivares de feijão e doses de calcário (t ha $\left.{ }^{-1}\right)$ aplicado superficialmente em plantio direto

\begin{tabular}{|c|c|c|c|c|}
\hline \multirow{2}{*}{ Cultivares } & \multicolumn{4}{|c|}{ Doses de calcário } \\
\hline & 0 & 1,8 & 3,6 & 5,4 \\
\hline Carioca * & $2.174 \mathrm{a}$ & $2.486 a b$ & $2.166 \mathrm{~b}$ & $2.505 a b$ \\
\hline IAC Carioca Eté * & $2.015 \mathrm{a}$ & $1.889 \mathrm{c}$ & $2.447 \mathrm{ab}$ & $2.027 \mathrm{~b}$ \\
\hline Pérola * & $2.191 \mathrm{a}$ & $2.582 a b$ & $2.333 a b$ & $2.363 \mathrm{ab}$ \\
\hline IAPAR $81^{(2)}$ & $2.025 \mathrm{a}$ & $2.184 \mathrm{bc}$ & $2.302 \mathrm{ab}$ & $2.655 \mathrm{a}$ \\
\hline Campeão 2 * & $2.491 \mathrm{a}$ & $2.772 \mathrm{a}$ & $2.836 \mathrm{a}$ & $2.711 \mathrm{a}$ \\
\hline
\end{tabular}

Médias seguidas de mesma letra na coluna, não diferem entre si pelo teste de Tukey a $5 \%$ de probabilidade $\left(\mathrm{DMS}=510 \mathrm{~kg}\right.$ ha $\left.{ }^{-1}\right) .\left({ }^{2}\right) \mathrm{Y}=111,56 \mathrm{x}+1990,3 ; \mathrm{R}^{2}=0,94^{* *}$. ${ }^{* *}$ : Significativo a $1 \%$ de probabilidade pelo teste de Tukey. ${ }^{*}$ = Regressão não significativa a $5 \%$ de probabilidade.

Tabela 4. Desdobramento da interação do tempo de cozimento (2003 e 2004), em função de cultivares de feijão e doses de calcário $\left(\mathrm{t} \mathrm{ha} \mathrm{a}^{-1}\right)$ aplicado superficialmente em plantio direto

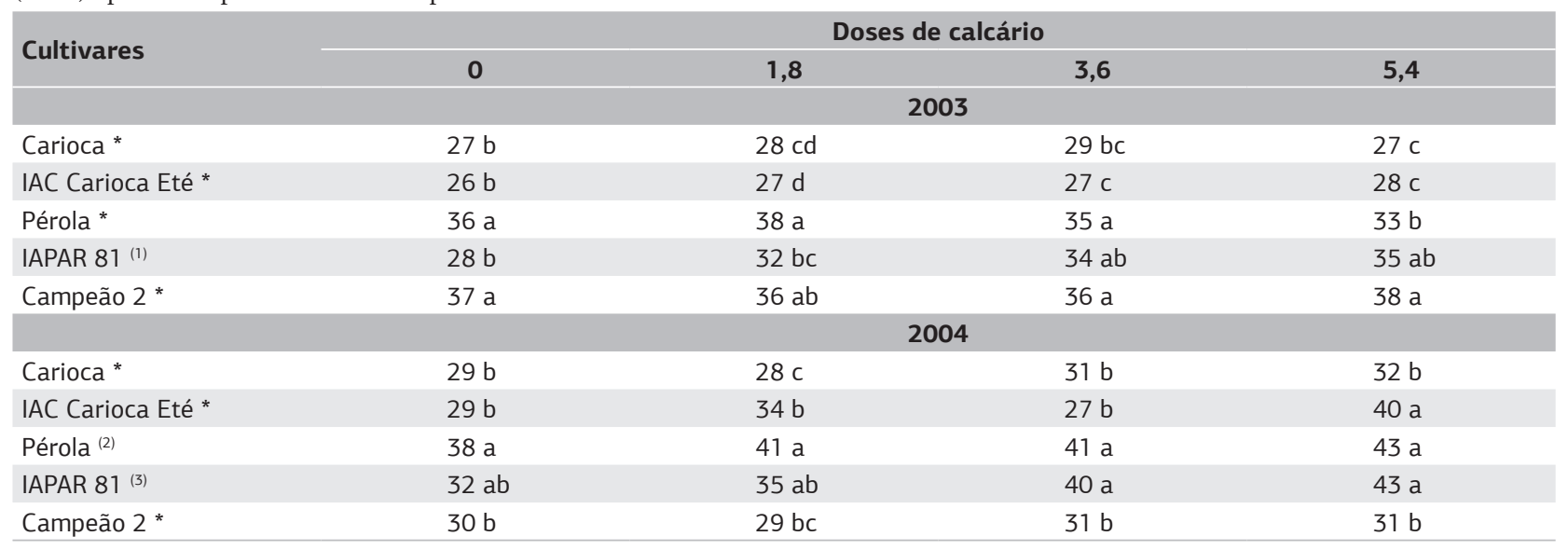

Médias seguidas de mesma letra na coluna, nấo diferem entre si pelo teste de Tukey a $5 \%$ de probabilidade

(') $\mathrm{Y}=1,2778 \mathrm{x}+28,8 ; \mathrm{R}^{2}=0,92^{* *} .{ }^{* *}$ Significativo a $1 \%$ de probabilidade pelo teste de Tukey.

( $\left.{ }^{2}\right) \mathrm{Y}=0,8333 \mathrm{x}+38,5 ; \mathrm{R}^{2}=0,88^{* *} .\left({ }^{3}\right) \mathrm{Y}=2,1111 \mathrm{x}+31,8 ; \mathrm{R}^{2}=0,98^{* *}$. ${ }^{* *}$ Significativo a $1 \%$ de probabilidade pelo teste de Tukey.

* = Regressão não significativa a $5 \%$ de probabilidade. 
Tabela 5. Grãos de casca dura (\%) e relação de hidratação dos grãos, em função de cultivares de feijão e doses de calcário (t ha $\left.{ }^{-1}\right)$ aplicado superficialmente em plantio direto

\begin{tabular}{|c|c|c|c|c|}
\hline \multirow{2}{*}{ Tratamento } & \multicolumn{2}{|c|}{ Grãos de casca dura (\%) } & \multicolumn{2}{|c|}{ Relação de hidratação } \\
\hline & 2003 & 2004 & 2003 & 2004 \\
\hline \multicolumn{5}{|l|}{ Cultivares } \\
\hline Carioca & $0,75 d$ & $1,24 \mathrm{~b}$ & $1,94 \mathrm{a}$ & $1,96 \mathrm{a}$ \\
\hline IAC Carioca Eté & $2,34 \mathrm{c}$ & $1,85 \mathrm{a}$ & $1,93 \mathrm{a}$ & $1,97 \mathrm{a}$ \\
\hline Pérola & $4,34 \mathrm{a}$ & $1,35 b$ & $1,94 \mathrm{a}$ & $1,95 \mathrm{a}$ \\
\hline IAPAR 81 & $3,30 \mathrm{~b}$ & $0,90 \mathrm{c}$ & $1,95 \mathrm{a}$ & $1,95 \mathrm{a}$ \\
\hline Campeão 2 & $1,12 \mathrm{~d}$ & $0,18 d$ & $1,96 \mathrm{a}$ & $1,99 a$ \\
\hline CV (\%) & 5,3 & 6,7 & 1,2 & 1,7 \\
\hline \multicolumn{5}{|l|}{ Doses de calcário } \\
\hline 0 & 0,30 & 1,26 & 1,96 & 1,97 \\
\hline 1,8 & 0,33 & 1,03 & 1,95 & 1,98 \\
\hline 3,6 & 0,30 & 1,30 & 1,96 & 1,98 \\
\hline 5,4 & 0,80 & 1,36 & 1,94 & 1,99 \\
\hline CV (\%) & 6,7 & 8,9 & 1,4 & 2,9 \\
\hline F Cultivares (C) & * & * & n.s. & n.s. \\
\hline F Doses (D) & n.s. & n.s. & n.s. & n.s. \\
\hline F Interação C x D & n.s. & n.s. & n.s. & n.s. \\
\hline R.L. & n.s. & n.s. & n.s. & n.s. \\
\hline R.Q. & n.s. & n.s. & n.s. & n.s. \\
\hline
\end{tabular}

Médias seguidas de mesma letra, na coluna, dentro do fator cultivares, não diferem entre si a $5 \%$ pelo teste de Tukey. ${ }^{\text {n.s }}=$ Năo significativo. ${ }^{*}$ significativo a $5 \%$ de probabilidade pelo teste $\mathrm{F}$.

Tabela 6. Regressão entre o tempo de máxima hidratação e a quantidade de água absorvida pelos grãos de feijão (2003), em função de cultivares de feijáo e doses de calcário $\left(\mathrm{t} \mathrm{ha}^{-1}\right)$ aplicado superficialmente em plantio direto $\left.{ }^{1}\right)$

\begin{tabular}{|c|c|c|c|c|}
\hline Tratamento & & Equação de Regressão & $\mathbf{R}^{2}$ & $\begin{array}{l}\text { Tempo de máxima } \\
\text { hidratação }\end{array}$ \\
\hline Cultivares & Doses & & & (horas:minutos) \\
\hline \multirow{4}{*}{ Carioca } & 0 & $Y=-0,0001 x^{2}+0,1279 x+4,4613$ & 0,98 & $10: 39$ \\
\hline & 1,8 & $Y=-0,0001 x^{2}+0,1317 x+6,135$ & 0,96 & $10: 58$ \\
\hline & 3,6 & $Y=-0,0001 x^{2}+0,1246 x+7,3956$ & 0,95 & $10: 22$ \\
\hline & 5,4 & $Y=-0,00009 x^{2}+0,1194 x+4,4387$ & 0,97 & 11:03 \\
\hline Média & - & - & - & $10: 46$ \\
\hline \multirow{4}{*}{ IAC Carioca Eté } & 0 & $Y=-0,0001 x^{2}+0,1344 x+1,1181$ & 0,99 & $11: 12$ \\
\hline & 1,8 & $Y=-0,0001 x^{2}+0,1277 x+2,5403$ & 0,99 & $10: 38$ \\
\hline & 3,6 & $Y=-0,00009 x^{2}+0,1161 x+2,9051$ & 0,99 & $10: 45$ \\
\hline & 5,4 & $Y=-0,00009 x^{2}+0,122 x+2,789$ & 0,99 & $11: 17$ \\
\hline Média & - & - & - & $10: 58$ \\
\hline \multirow{4}{*}{ Pérola } & 0 & $Y=-0,00006 x^{2}+0,0971 x+2,406$ & 0,99 & $13: 29$ \\
\hline & 1,8 & $Y=-0,00007 x^{2}+0,1174 x+2,7676$ & 0,99 & $13: 58$ \\
\hline & 3,6 & $Y=-0,00005 x^{2}+0,0927 x+1,118$ & 0,99 & $15: 27$ \\
\hline & 5,4 & $Y=-0,00006 x^{2}+0,0976 x+2,2933$ & 0,99 & $13: 33$ \\
\hline Média & - & - & - & 14:07 \\
\hline \multirow{4}{*}{ IAPAR 81} & 0 & $Y=-0,0001 x^{2}+0,1242 x+4,8318$ & 0,98 & $10: 21$ \\
\hline & 1,8 & $Y=-0,0001 x^{2}+0,1237 x+5,5937$ & 0,97 & $10: 18$ \\
\hline & 3,6 & $Y=-0,0001 x^{2}+0,1228 x+4,776$ & 0,97 & $10: 14$ \\
\hline & 5,4 & $Y=-0,0001 x^{2}+0,1248 x+4,1423$ & 0,98 & $10: 24$ \\
\hline Média & - & - & - & 10:19 \\
\hline \multirow{4}{*}{ Campeão 2} & 0 & $Y=-0,00008 x^{2}+0,1184 x+3,4485$ & 0,98 & $12: 20$ \\
\hline & 1,8 & $Y=-0,00009 x^{2}+0,1243 x+3,3947$ & 0,98 & $11: 31$ \\
\hline & 3,6 & $Y=-0,00008 x^{2}+0,1054 x+3,8439$ & 0,98 & $10: 58$ \\
\hline & 5,4 & $Y=-0,00008 x^{2}+0,1124 x+1,7726$ & 0,99 & $11: 43$ \\
\hline Média & - & - & - & $11: 38$ \\
\hline
\end{tabular}

(') x: tempo para hidrataçấo (minutos); Y: quantidade de água absorvida (mL). 
Tabela 7. Regressão entre o tempo de máxima hidratação e a quantidade de água absorvida pelos grãos de feijão (2004), em função de cultivares de feijão e doses de calcário $\left(\mathrm{t} \mathrm{ha}^{-1}\right)$ aplicado superficialmente em plantio direto $\left({ }^{1}\right)$

\begin{tabular}{|c|c|c|c|c|}
\hline Tratamento & & Equação de regressão & $\mathbf{R}^{2}$ & $\begin{array}{l}\text { Tempo de máxima } \\
\text { hidratação }\end{array}$ \\
\hline Cultivares & Doses & & & (horas:minutos) \\
\hline \multirow{4}{*}{ Carioca } & 0 & $Y=-0,0001 x^{2}+0,1375 x+5,7789$ & 0,94 & $11: 27$ \\
\hline & 1,8 & $Y=-0,0001 x^{2}+0,1327 x+5,3801$ & 0,95 & $11: 03$ \\
\hline & 3,6 & $Y=-0,0001 x^{2}+0,1305 x+5,5602$ & 0,95 & $10: 52$ \\
\hline & 5,4 & $Y=-0,0001 x^{2}+0,1338 x+5,6381$ & 0,95 & 11:09 \\
\hline Média & - & - & - & $11: 08$ \\
\hline \multirow{4}{*}{ IAC Carioca Eté } & 0 & $Y=-0,0001 x^{2}+0,1405 x+4,8253$ & 0,96 & $11: 42$ \\
\hline & 1,8 & $Y=-0,0001 x^{2}+0,1428 x+4,9456$ & 0,96 & $11: 54$ \\
\hline & 3,6 & $Y=-0,0001 x^{2}+0,1463 x+5,8112$ & 0,94 & $12: 11$ \\
\hline & 5,4 & $Y=-0,0001 x^{2}+0,1453 x+4,5854$ & 0,96 & $12: 06$ \\
\hline Média & - & - & - & $11: 58$ \\
\hline \multirow{4}{*}{ Pérola } & 0 & $Y=-0,0001 x^{2}+0,1566 x+4,5294$ & 0,97 & $13: 03$ \\
\hline & 1,8 & $Y=-0,0001 x^{2}+0,1532 x+3,9764$ & 0,98 & $12: 45$ \\
\hline & 3,6 & $Y=-0,0001 x^{2}+0,1616 x+4,5117$ & 0,97 & $13: 27$ \\
\hline & 5,4 & $Y=-0,0001 x^{2}+0,1635 x+4,5459$ & 0,98 & $13: 37$ \\
\hline Média & - & - & - & $13: 13$ \\
\hline \multirow{4}{*}{ IAPAR 81} & 0 & $Y=-0,0001 x^{2}+0,1482 x+8,0433$ & 0,94 & $12: 21$ \\
\hline & 1,8 & $Y=-0,0001 x^{2}+0,1408 x+7,9661$ & 0,94 & $11: 43$ \\
\hline & 3,6 & $Y=-0,0001 x^{2}+0,1474 x+8,1832$ & 0,93 & $12: 17$ \\
\hline & 5,4 & $Y=-0,0001 x^{2}+0,1385 x+7,7941$ & 0,93 & $11: 32$ \\
\hline Média & - & - & - & $11: 58$ \\
\hline \multirow{4}{*}{ Campeão 2} & 0 & $Y=-0,0001 x^{2}+0,1408 x+5,4309$ & 0,97 & $11: 43$ \\
\hline & 1,8 & $Y=-0,0001 x^{2}+0,1417 x+6,2779$ & 0,96 & $11: 48$ \\
\hline & 3,6 & $Y=-0,0001 x^{2}+0,1406 x+6,0975$ & 0,96 & $11: 42$ \\
\hline & 5,4 & $Y=-0,0001 x^{2}+0,1401 x+5,8138$ & 0,96 & $11: 40$ \\
\hline Média & - & - & - & $11: 43$ \\
\hline
\end{tabular}

(') x: tempo para hidrataçấo (minutos); Y: quantidade de água absorvida (mL).

De forma geral, para a relação de hidratação, observou-se que após 12 horas de embebição, os grãos absorveram massa em água aproximadamente igual à sua massa inicial, ou seja, valores muito próximos de 2,0 (Tabela 5), concordando com os resultados obtidos por MoraEs et al. (1998). Esses autores verificaram que a relação de hidratação também ficou próxima de 2,0, não havendo interferência das doses de calcário e gesso testadas. Segundo LaMSANCHEs et al. (1990), a variabilidade em feijão quanto à presença de gráos impermeáveis é devido ao processo de defesa da própria planta diante de alguma situação desfavorável ao seu desenvolvimento, citando que, em condiçôes de excesso de precipitação pluvial por ocasião da semeadura, as sementes normais apodrecem, enquanto as impermeáveis suportam esse período e posteriormente germinam. Esses autores também relataram que esse tipo de comportamento da planta pode ser responsável pelas diferenças que ocorrem com a qualidade dos grãos de ano para ano e entre distintos cultivos durante o mesmo ano.

As equações de regressão entre o tempo de hidratação e a quantidade de água absorvida pelos grãos de feijāo, em 2003, evidenciaram que o período de máxima hidrataçáo variou de $10 \mathrm{~h} 14 \mathrm{~min}$ a $15 \mathrm{~h} 27 \mathrm{~min}$, tendo diferença de 5 h13min (Tabela 6). Esses resultados foram obtidos pelas cultivares IAPAR 81 e Pérola, na dose de 3,6 t ha ${ }^{-1}$ de calcário.
Verificou-se, em 2004, que o tempo de máxima hidrataçâo variou de $10 \mathrm{~h} 52 \mathrm{~min}$ a $13 \mathrm{~h} 37 \mathrm{~min}$, obtidos pelas cultivares Carioca e Pérola, nas doses de 3,6 e 5,4 t ha ${ }^{-1}$ de calcário, respectivamente (Tabela 7). No segundo ano a diferença foi de $2 \mathrm{~h} 45 \mathrm{~min}$, tendo reduçáo de aproximadamente $50 \%$ na variação do tempo para atingir a máxima hidratação dos grãos de um ano para o outro. Portanto, pode-se inferir que a capacidade de hidratação dos grãos de feijão é uma característica influenciada pela interação genótipos $\mathrm{x}$ ambiente.

O tempo médio para a máxima hidratação das cultivares de feijão, não ultrapassou a 12 horas, com exceção da cultivar Pérola que obteve $14 \mathrm{~h} 07 \mathrm{~min}$ e $13 \mathrm{~h} 13 \mathrm{~min}$, em 2003 e 2004 respectivamente (Tabela 7). Assim, pode-se inferir que, na média, com a cultivar Pérola não houve desempenho satisfatório quanto ao tempo para a máxima hidratação dos grãos, visto que, geralmente, os grãos de feijão são deixados em embebição, da noite anterior ao preparo até a manhã do dia seguinte, por período de aproximadamente 12 horas, conforme informaçôes contidas em Lemos et al. (2004) e SiLva et al. (2006).

\section{CONCLUSÕES}

1. As cultivares de feijão têm desempenho produtivo distinto em função das doses de calcário aplicadas 
superficialmente, no sistema plantio direto, destacando-se a cultivar Campeáo 2 como a mais produtiva.

2. Nota-se a influência da interação dos fatores cultivares e das doses de calcário para o tempo de cozimento, havendo na cultivar IAPAR 81 aumento dessa característica, em função do incremento das doses de calcário.

3. Os valores do teor de proteína bruta e da relação de hidratação dos grãos não variam em função das doses de calcário e das cultivares de feijão.

\section{REFERÊNCIAS}

AMBROSANO, E.J.; TANAKA, R.T.; MASCARENHAS, A.A.; RAIJ, B. van; QUAGGIO, J.A.; CANTARELLA, H. Feijão. In: RAIJ, B. van; CANTARELA, H.; QUAGGIO, J.A.; FURLANI, A.M.C. Recomendaçôes de adubaçáo e calagem para o Estado de São Paulo. 2.ed. Campinas: IAC, 1997. p.189-195. (Boletim Técnico 100)

BARBOSA FILHO, M.P.; FAGERIA, N.K.; ZIMMERMANN, F.J.P. Atributos de fertilidade do solo e produtividade do feijoeiro e da soja influenciados pela calagem em superfície e incorporada. Ciência e Agrotecnologia, v.29, p.507-514, 2005.

DIDONET, A.D. Respostas da cultivar de feijoeiro comum Pérola ao choque térmico com altas temperaturas. Santo Antônio de Goiás: Embrapa-CNPAF, 2002. 3p. (Comunicado Técnico, 39)

EMPRESA BRASILEIRA DE PESQUISA AGROPECUÁRIA. Sistema Brasileiro de Classificação dos Solos. Rio de Janeiro: EMBRAPA/CNPSO, 2006. 315p.

LAM-SANCHEZ, A.; DURIGAN J.F.; CAMPOS, S.L.; SILVESTRE, S.R.; PEDROSO, P.A.C.; BANZATTO, D.A. Efeitos da época de semeadura sobre a composição química e características físico-químicas de grãos de Phaseolus vulgaris L., Phaseolus angularis (Wild) Wright e Vigna unguiculata (L.) Walp. Alimentos e Nutrição, v.2, p. 35-44, 1990.

LEMOS, L.B.; OLIVEIRA, R.S.; PALOMINO, E.C.; SILVA, T.R.B. Características agronômicas e tecnológicas de genótipos de feijão do grupo comercial carioca. Pesquisa Agropecuária Brasileira, v.39, p.319-326, 2004.

MARSCHNER, H. Mineral nutrition of higher plants. London: Academic Press, 1995. 889p.

MELLO, J.C.A.; VILLAS BÔAS, R.L.; LIMA, E.V.; CRUSCIOL, C.A.C.; BÜLL, L.T. Alteraçôes nos atributos químicos de um Latossolo distroférrico decorrentes da granulometria e doses de calcário em sistemas plantio direto e convencional. Revista Brasileira de Ciência do Solo, v.27, p.553-561, 2003.
MORAES, J.F.L.; BELLINGIERI, P.A.; FORNASIERI FILHO, D.; GALLON, J.A. Efeito de doses de calcário e de gesso na cultura do feijoeiro (Phaseolus vulgaris L.) cv. Carioca-80. Scientia Agricola, v.55, p.63-69, 1998.

PROCTOR, J.R.; WATTS, B.M. Development of a modified Mattson bean cooker procedure base don sensory panel cookability evaluation. Canadian Institute of Food Science and Techonology Journal, v.20, p.9-14, 1987.

RAIJ, B. van.; QUAGGIO, J.A. Métodos de análise de solo para fins de fertilidade. Campinas: Instituto Agronômico, 1983. 31p. (Boletim Técnico, 81)

ROSOLEM, C.A. Calagem e adubação mineral. In: ARAUJO, R.S.; RAVA, C.A.; STONE, L.F.; ZIMMERMANN, M.J.O. (Coord.). Cultura do feijoeiro comum no Brasil. Piracicaba: Potafos, 1996, p.353-385.

SARRUGE, J.R.; HAAG, H.P. Análises químicas em plantas. Piracicaba: ESALQ, 1974. 56p.

SARTORI, M.R. Armazenamento. In: ARAUJO, R.S.; RAVA, C.A.; STONE, L.F.; ZIMMERMANN, M.J.O. (Coord.). Cultura do feijoeiro comum no Brasil. Piracicaba: Potafos, 1996. p.543558.

SILVA, L.M.; LEMOS, L.B.; CRUSCIOL, C.A.C.; FELTRAN, J.C. Sistema radicular de cultivares de feijão em resposta à calagem. Pesquisa Agropecuária Brasileira, v.39, p.701-707, 2004.

SILVA, L.M.; LEMOS, L.B.; CRUSCIOL, C.A.C.; MATEUS, G.P.; FELTRAN, J.C. Eficiência de utilização de nutrientes em cultivares de feijão em razão da calagem. Revista de Agricultura, v.82, p.184-196, 2007.

SILVA, T.R.B.; LEMOS, L.B.; TAVARES, C.A. Produtividade e característica tecnológica de grãos em feijoeiro adubado com nitrogênio e molibdênio. Pesquisa Agropecuária Brasileira, v.41, p.739-745, 2006.

THUNG, M.D.T.; OLIVEIRA, I.P. Problemas abióticos que afetam a produção de feijoeiro e seus métodos de controle. Santo Antonio de Goiás: Embrapa-CNPAF, 1998. 172p.

VALE, L.S.R.; NAKAGAWA, J. Efeitos de doses de calcário na qualidade de sementes de feijão (Phaseoulus vulgaris L.). Revista Brasileira de Sementes, v.18, p.129-133, 1996. 